\title{
High Voltage Research (Breakdown Strengths of Gaseous and Liquid Insulators) Second Quarterly Report (Period Ending September 30, 1976)
}
L. G. Christophorou
D. R. James
R. Y. Pai
M. O. Pace
R. A. Mathis
D. W. Bouldin
D. E. Tittle 


\section{DISCLAIMER}

This report was prepared as an account of work sponsored by an agency of the United States Government. Neither the United States Government nor any agency Thereof, nor any of their employees, makes any warranty, express or implied, or assumes any legal liability or responsibility for the accuracy, completeness, or usefulness of any information, apparatus, product, or process disclosed, or represents that its use would not infringe privately owned rights. Reference herein to any specific commercial product, process, or service by trade name, trademark, manufacturer, or otherwise does not necessarily constitute or imply its endorsement, recommendation, or favoring by the United States Government or any agency thereof. The views and opinions of authors expressed herein do not necessarily state or reflect those of the United States Government or any agency thereof. 


\section{DISCLAIMER}

Portions of this document may be illegible in electronic image products. Images are produced from the best available original document. 


\section{Printed in the United States of America. Available from National Technical Information Service \\ U.S. Department of Commerce \\ 5285 Port Royal Road, Springfield, Virginia 22161 \\ Price: Printed Copy $\$ 4.00$; Microfiche $\$ 3.00$}

This report was prepared as an account of work sponsored by the United States Government. Neither the United States nor the Energy Research and Development Administration/United States Nuclear Regulatory Commission, -nor any of their employees, nor any of their contractors, subcontractors, or their employees, makes any warranty, express or implied, or assumes any legal liability or responsibility for the accurary, renmpleteness or usefulness of any information, apparatus. product or process disclosed, or represents that its use would not infringe privately owned rights. 
ORNL/TM-5713

Contract No. W-7405-eng-26

Activity No. HA $0201000^{\circ}$

HEALTH PHYSICS DIVISION

HIGH VOLTAGE RESEARCH (BREAKDOWN STRENGTHS OF

GASEOUS AND LIQUID INSULATORS)

Second Quarterly Report

(Period Ending September 30, 1976)

L. G. Christophorou, D. R. James, R. Y. Pai, M. 0. Pace, R. A. Mathis, D. W. Bouldin, and D. E. Tittle

Date Published: December 1976

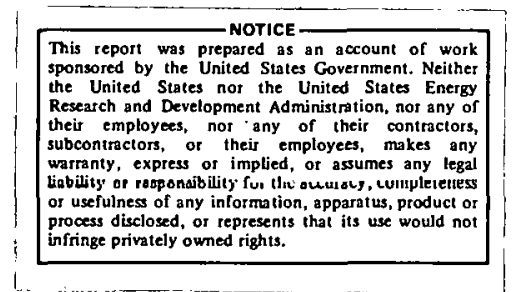

NOTICE This document contains information of a preliminary nature. It is subject to revision or correction and therefore does not represent a final report.

OAK RIDGE NATIONAL LABORATORY

Oak Ridge, Tennessee 37830

operated by

UNION CARBIDE CORPORATION

for the

ENERGY RESEARCH AND DEVELOPMENT ADMINISTRATION 
THIS PAGE

\section{WAS INTENTIONALLY LEFT BLANK}




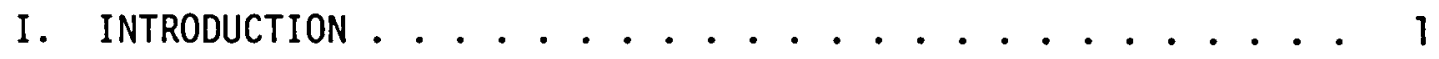

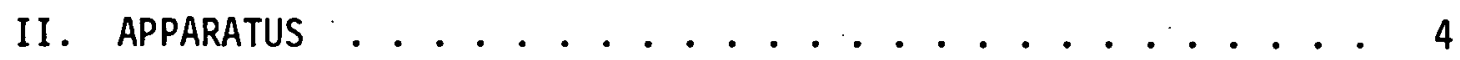

III. BREAKDOWN STRENGTH MEASUREMENTS . . . . . . . . 10

IV. BASIC STUDIES .................... 17

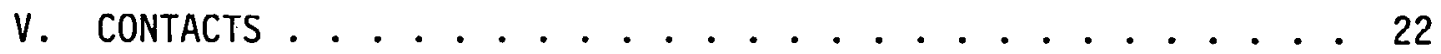

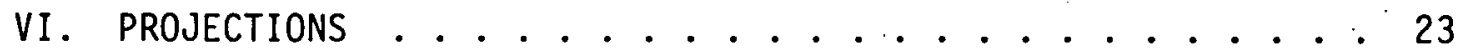

VII. REFERENCES ..................... 24 


\section{INTRODUCTION}

This is the second report of a project begun at Oak Ridge Nations. Laboratory (ORNL) to apply expertise on electron-molecule interactions and relevant basic physicochemical knowledge to the need for energy economy and independence by developing improved insulating materials for high voltage power transmission, with the potential of enormous savings. The first report (ORNL/TM-5604) ${ }^{1}$ covered progress to June $30,1976$. This report covers the quarter July 1-September 30, 1976.

The experience, knowledge and capability of the Atomic, Molecular and High Voltage Physics Group within the Health Physics Division in the area of fundamental electron-molecule interactions is being used to design better insulating gaseous systems. In this fundamental area the group has played a leading role for over a decade and a half, and its. continuing vitality offers the capability to obtain desired data not yet available.

The best insulating systems are anticipated to be mixtures designed as to components and pressures using fundamental physicochemical data obtained primarily from studies on interactions of slow electrons with atomic and molecular. gases. More specifically, the gaseous components should be chosen to act as a system which provides the "best". effective combination of electron thermalizing (slowing down) and electron scavenging (forming relatively immobile negative ions) to inhibit breakdown by electrons. This involves many different but coupled energy-dependent interactions between the gas and the electrons, which possess a rather wide distribution of energies. Especially significant are the electron attachment and electron energy loss processes in the range from thermal 
to $\approx 2$ to $3 \mathrm{eV}$ (generally subexcitation energies). It is very important that electrons are captured or slowed down before they escape this energy range.

In addition to our fundamental goal to identify the best gaseous (and liquid) insulating systems, a number of other longer-range goals are being considered in current activities. One is the nontrivial problem of extending current uniform field results to the nonuniform field conditions characteristic of power apparatus, and ultimately to practical engineering design guidelines. Also being considered are chemical properties, economics, temperature effects and numerous practical "spin-offs" from this research such as the detection and prevention or diversion of incipient breakdown. The effects of solid particles and breakdown products will be studied for the best insulators.

In addition to the project staff described in the last report, we now have Mr. David Tittle, who joined the project in September 1976. He is an electrical engineering graduate student. from The University of Tennessee and performs research for his M.S. degree on this project. An additional office has been secured for staff this quarter.

During this quarter, both breakdown apparatuses have been in operation and have been employed to study unitary and multicomponent insulating gases at various pressures and gaps, while improvements and additions in the apparatuses continued to be made. Design of a third apparatus has begun to attain the voltage, pressure and gap necessary for breakdown studies at higher values of Pd (pressure times gap). Breakdown strength measurements have been performed for a number of unitary and multicomponent gases. Correlation has been assessed between fundamental electron- 
molecule interactions and molecular structure, and breakdown strength. A more detailed study of diverters has begun to develop them as protecting devices for power systems and experimental apparatus.

In the next quarter our work on the correlation of fundamental processes and properties of gases and their breakdown strengths will continue. The study of unitary systems will move from apparatus 1 to apparatus 2 to attain higher values of $\mathrm{Pd}$, while the study of mixtures will shift to apparatus 1 for economy of gases. Diverters will be studied as a new, small, separate experiment. A chamber for the $300 \mathrm{kV}$ power supply on order will be designed and constructed. New electrodes with cylindrical geometries and varied degrees of roughness will be built. 


\section{APPARATUS}

The two breakdown apparatuses described in the previous report ${ }^{1}$ have been in operation this quarter, with initial checkout of apparatus 2 complete. Some small modifications have been made in these apparatuses since their description in the first report.

For apparatus 1, a new controller (which incorporates the features of the controller on apparatus 2 with a time-of-day printout alongside each data point) is near completion in hard-wired form. The teletype and associated BCD-ASCII converter for apparatus 1 have been received. A feedback circuit has been desiqned and put into operation in hreadboarded form to replace the Superior Electric Company "position detector" in apparatus 1 because the replaced device proved difficult to service, while the replacement is easily serviced with ORNL-stocked parts.

The diverter box has been rebuilt for apparatus 1, with two improvements: the previous diverter circuit was replaced with one modeled after that of apparatus 2 to give more reliable diverter action, and the new geometry and absence of capacitors allowed the voltage in apparatus 1 to be raised to $\approx 50 \mathrm{kV}$ on the test gap. The new diverter circuit is almost identical to that reported previously, except that the apparatus 1 diverter employs $1 \frac{1}{2}$-inch-diameter spherical stainless steel electrodes.

Apparat.us ? has operated satisfactorily this quarter with no major problems. A vacuum-tight stainless steel cylinder of approximately 6.5 liters volume was constructed and placed in the region under the electrodes to reduce the volume of test gas required in the chamber by about $20 \%$. A platform has been designed and is being fabricated to hold the lower electrode off the chamber sides by insulated supports and to replace 
the present less steady method of supporting the lower electrode on the high voltage feedthrough shaft. A mechanical forepump has been added to apparatus 2 for cases when frequent recycling of gas is desired.

During this quarter, a new chamber has been under design to operate in conjunction with the new ( $300 \mathrm{kV})$ power supply on order, to utilize much higher values of $\mathrm{Pd}$ (pressure times gap spacing) by providing higher pressure and voltage. The high voltage will be introduced into one end of the cylindrical chamber by a bushing which protrudes into the chamber, introducing the end of the cable to the electrode position and thus occupying considerable volume to save gas. This arrangement has been worked out with Delta Ray Corporation at a considerable savings in money and gas volume when compared with the previous ceramic feedthroughs which protrude out of the chamber. The electrodes will be interchangeable with the uniform field electrodes described in the previous report for apparatus 2. This new chamber will require about 10 liters of test gas and will have improved mechanical control of electrode position, as well as the required ports and pumping.

Considerable experimental study has been made on the diverter in apparatus 2 as a start toward developing diverters for power apparatus, as well as for these experiments. Because of the potential of the diverter as a protective device for underground cable, experimentation has begun concerning its operating characteristics. It should be able to discharge the excess energy from a cable section in a very short time; therefore, tests have begun concerning the speed of the diverter reaction following a breakdown in the "cable" (test chamber). The graph in Fig. 1 shows voltage versus time of reaction for two polarity arrangements. It 


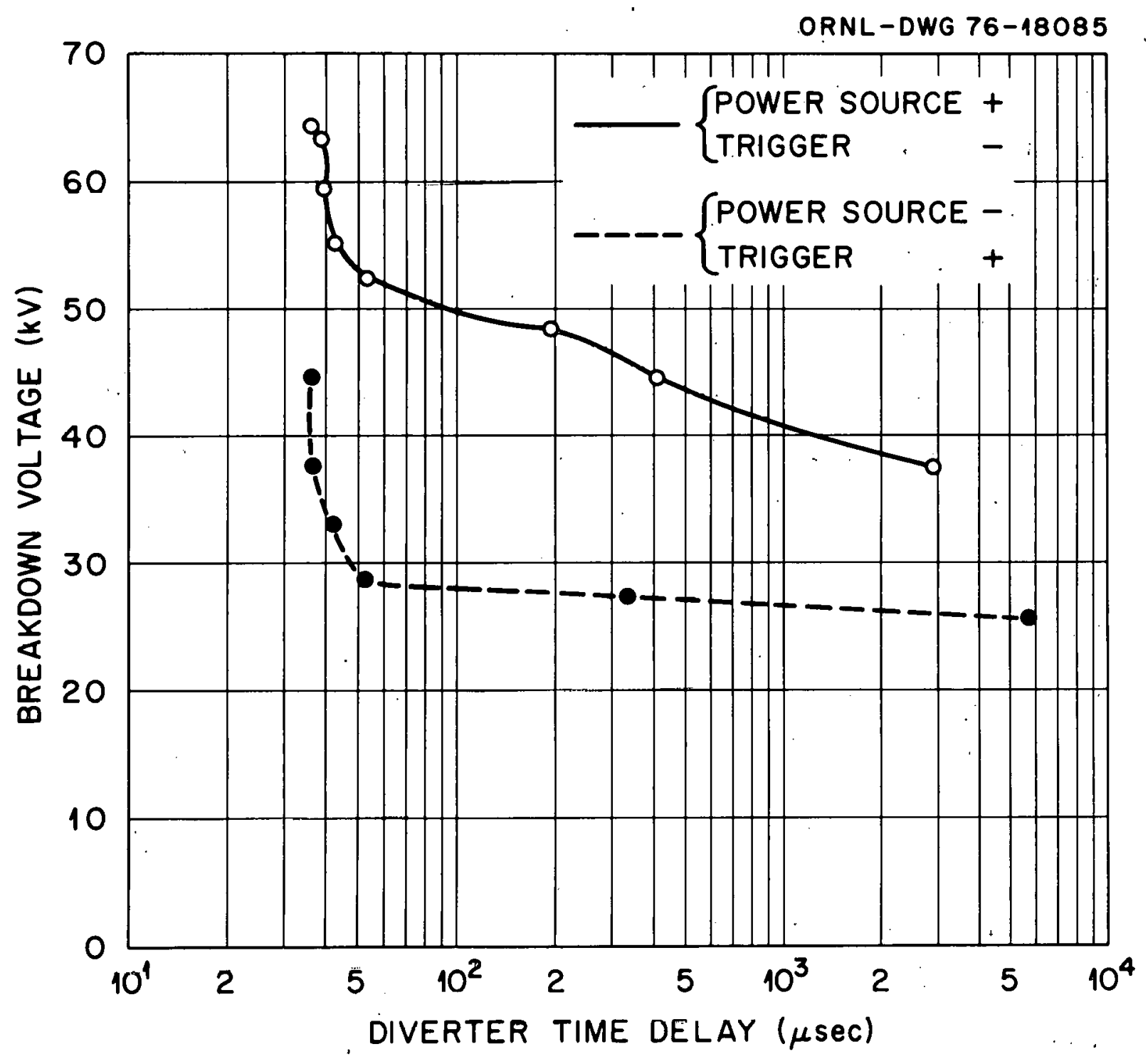

Fig. 1. Breakdown voltage at 1 -inch gap versus diverter time delay. 
seems to show the workings of two different mechanisms: a slow and a fast one. Further research into this area will proceed next quarter. Tests must also be run concerning the reliability of a triggered breakdown. The graph in Fig. 2 shows a probability curve for triggered breakdown with two polarity arrangements. These are necessary to establish a working range for the diverter in terms of the gap, geometry and voltage. The working range for reliable triggering can be tabulated versus $h / s$, where $h$ is the distance into the gap of the trigger electrode insulator, and $s$ is the total gap distance. In this $h / s$ form our data have not been reconciled with those in a paper published by Korshunov et al. of the Soviet Union. ${ }^{2}$ The Russians concluded that the working range increases with $\mathrm{h} / \mathrm{s}$, while giving no polarity for trigger. or main voltages. Our data concerns all four polarity possibilities and indicate varying relations between working range and $\mathrm{h} / \mathrm{s}$ values. Therefore, these data are still under investigation.

Another representation of working range is the ratio $\frac{v_{s}-v_{l}}{v_{s}}$, where $V_{s}$ is the untriggered gap breakdown voltage, and $V_{l}$ is the lowest gap voltage at which triggered breakdown is reliable. In one case a ratio of approximately $75 \%$ was obtained in our experiments, which is a better result than any we have yet been able to find in the literature. This will be given greater attention in the quarter to come.

While much of the present data is in agreement with that of other researchers, much of the data to come will be in new regimes. With the increased interest in this area, a small separate diverter experiment is being assembled which will allow for full-time research on this subject. The new experiment will begin with two 1.5-inch-diameter stainless steel 


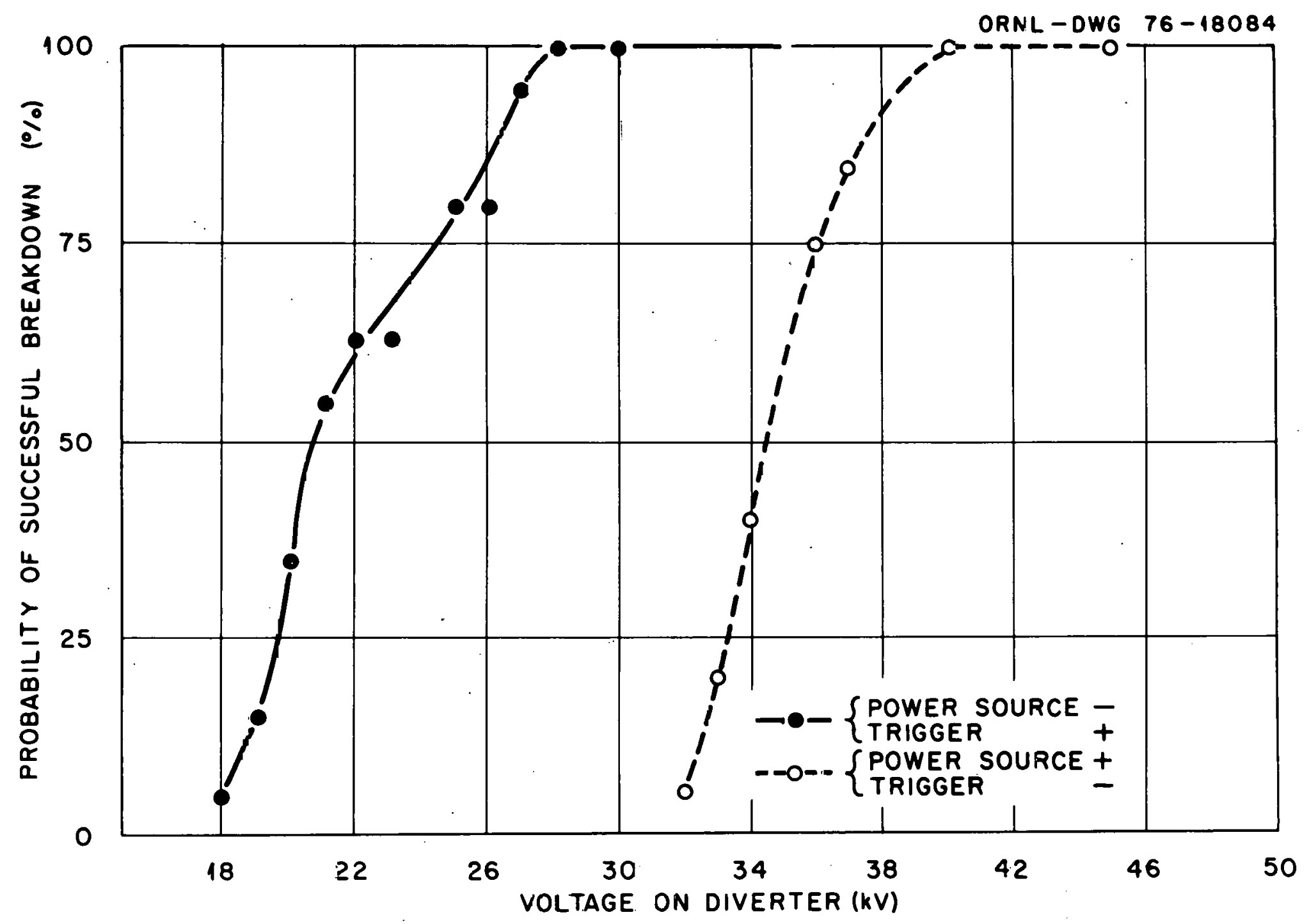

$\infty$

Fig. 2. Prabability of triggered breakdown of 1-inch gap versus voltage on diverter. 
spheres with a trigger electrode of 0.166 -inch diameter through the ground electrode and insulated from it. The trigger pulse is, as in apparatus 2, provided by an Accel 35355 electronic ignition amplifier and an Accel 14001 "super coil" powered by a 12-volt battery. Some of the matters of initial interest are the energy dissipation capabilities of the diverter gap, further investigation of the slow and fast mechanisms of breakdown, and collection of data involving parameters such as gap length or trigger protrusion. Long-range plans involve testing of the diverter in different gases where the possibility exists of increasing the energy dissipation properties and/or speed of breakdown.

In this quarter, also, effort has been put into identifying apparatus needed in the future. Specific items studied and discussed with vendors were the following: digital voltmeters, high voltage feedthroughs, highpressure linear-motion feedthroughs, strip chart recorders, image converter cameras, impulse voltage generators, image intensifiers, high voltage multimeter, partial discharge detector, storage oscilloscope, high voltage power supplies, chambers, pumps and RFI shielding cages. A number of the above $i$ tems have been received this quarter while others are. still on order.

An appreciable amount of construction and improvement work on the cages, gas manifolds and chambers has also been made. 
III . BREAKDOWN STRENGTH MEASUREMENTS

Unitary Systems (iso- $\mathrm{C}_{4} \mathrm{~F}_{8}$ and $\mathrm{C}_{4} \mathrm{~F}_{6}$ )

Preliminary investigations on iso- $_{4} \mathrm{~F}_{8}$ (perfluorobutene-2) as stated in the first quarterly report ${ }^{1}$ showed the iso form of $\mathrm{C}_{4} \mathrm{~F}_{8}$ to have a breakdown strength approximately $75 \%$ higher than that of $\mathrm{SF}_{6}$ and 25 to $28 \%$ higher than that of the cyclic form, $\mathrm{C}_{4} \mathrm{~F}_{8}$ (octafluorucyclobutane). During this quarter, more extensive measurcments on the breakduwn strength of iso- $\mathrm{C}_{4} \mathrm{~F}_{8}$ were made. In addition, measurements on the breakdown strength of the triple-bonded compound $\mathrm{C}_{4} \mathrm{~F}_{6}$ (hexafluorobutyne) have been made.

The measurements on the unitary systems were made on the $60 \mathrm{kV}$ apparatus (1) with sphere-plane electrodes. The experimental techniques used were the same as those described previously in the first quarterly report. ${ }^{1}$ Figure 3 summarizes the data taken this quarter on the unitary systems, iso- $C_{4} F_{8}$ and $C_{4} F_{6}$, for the $60 \mathrm{kV}$ sphere-plane apparatus. The breakdown voltage, $V_{S}$, in kilovolts is plotted against $P d$, where $P$ is the gas pressure and $d$ is the gap separation between the sphere surface and the plane. Included for completeness on this graph are the data for $C-\mathrm{C}_{4} \mathrm{~F}_{8}$ and $\mathrm{SF}_{6}$. Measurements of the breakdown voltage at Pd's of 1.0, 2.0 and 2.4 atm-mm for $c-C_{4} F_{8}$ and $\mathrm{SF}_{6}$ were repeated a number of times as has been indicaled in Fig. 9 of the rirsl quarterly report. ${ }^{l}$ In Fig. 3 of the present report we plot only the average value of $v_{s}$ at each value of Pd. The usual procedure was to make measurements alternatively between the test gas and $\mathrm{SF}_{6}$ in order to get an immediate comparison. A leastsquares fit straight line has been calculated and plotted in Fig. 3 for each gas. 


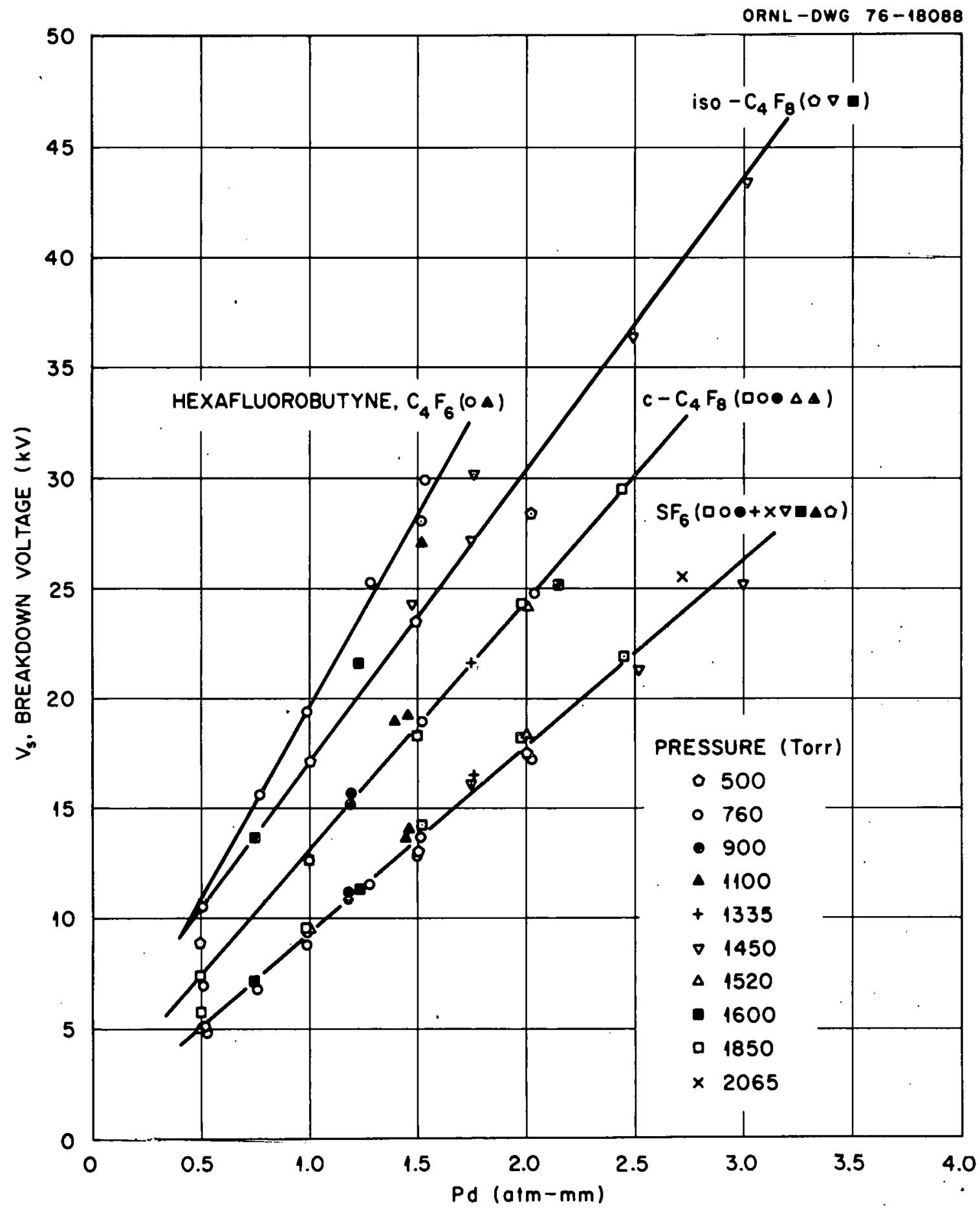

Fig. 3. Measured breakdown strengths of single gases (unitary systems). 
The breakdown strength of iso- $\mathrm{C}_{4} \mathrm{~F}_{8}$ was measured for pressures of 500,1450 and 1600 torr over the Pd range 0.5 to $3.0 \mathrm{~atm}-\mathrm{mm}$, where it is approximately 70 to $80 \%$ higher than that of $\mathrm{SF}_{6}$. There is also an increase of about $25 \%$ over the cyclic form.

$\mathrm{C}_{4} \mathrm{~F}_{6}$ exhibited a breakdown strength roughly 2.2 times higher than that of $\mathrm{SF}_{6}$ over the range of $\mathrm{Pd}$ from 0.5 to $1.5 \mathrm{~atm}-\mathrm{mm}$. Pressures used were 700 and 1100 torr. The scatter in the data was typically 0.5 to $6 \%$, which was quite satisfactory. The breakdown strengths for these systems (see Fig. 3) are expected to be even better at higher values of Pd, such as those employed in practice, because $V_{S}$ versus $P d$ lines may curve down faster for $\mathrm{SF}_{6}$ than for the fluorocarbons in Fig. 3. This can be seen from some early data ${ }^{3}$ plotted in Fig. 4.

We began studies of various gas mixtures in our newer apparatus (2). First, we made calibration measurements using $\mathrm{SF}_{6}$ and $\mathrm{N}_{2}$ to test the apparatus. The values we obtained are in agreement with published data, i.e., $90 \mathrm{kV} / \mathrm{atm}-\mathrm{cm}$ as the breakdown strength for $\mathrm{SF}_{6}$ and $26 \mathrm{kV} / \mathrm{atm}-\mathrm{cm}$ for $\mathrm{N}_{2}$.

With the calibration in hand we proceeded to test various mixtures of electron attaching and electron thermalizing gases. First, we tested the mixture $c-C_{4} F_{8}$ and $N_{2}$. In Fig. 5 the breakdown strength of these m1xtures as a function of the $c-C_{4} F_{8}$ percentage is shown. There is some evidence for a saturation effect in the $\mathrm{SF}_{6}-\mathrm{N}_{2}$ mixtures which is only slight in the $\mathrm{C}-\mathrm{C}_{4} \mathrm{~F}_{8}-\mathrm{N}_{2}$ mixtures.

Three-component mixtures of $\mathrm{C}-\mathrm{C}_{4} \mathrm{~F}_{8}-\mathrm{N}_{2}-\mathrm{CO}_{2}$ were also tried. These were chosen on the basis of the high electron attachment cross section of $\mathrm{C}-\mathrm{C}_{4} \mathrm{~F}_{8}$ and the slowing-down properties of $\mathrm{N}_{2}$ and $\mathrm{CO}_{2}$. Results are 


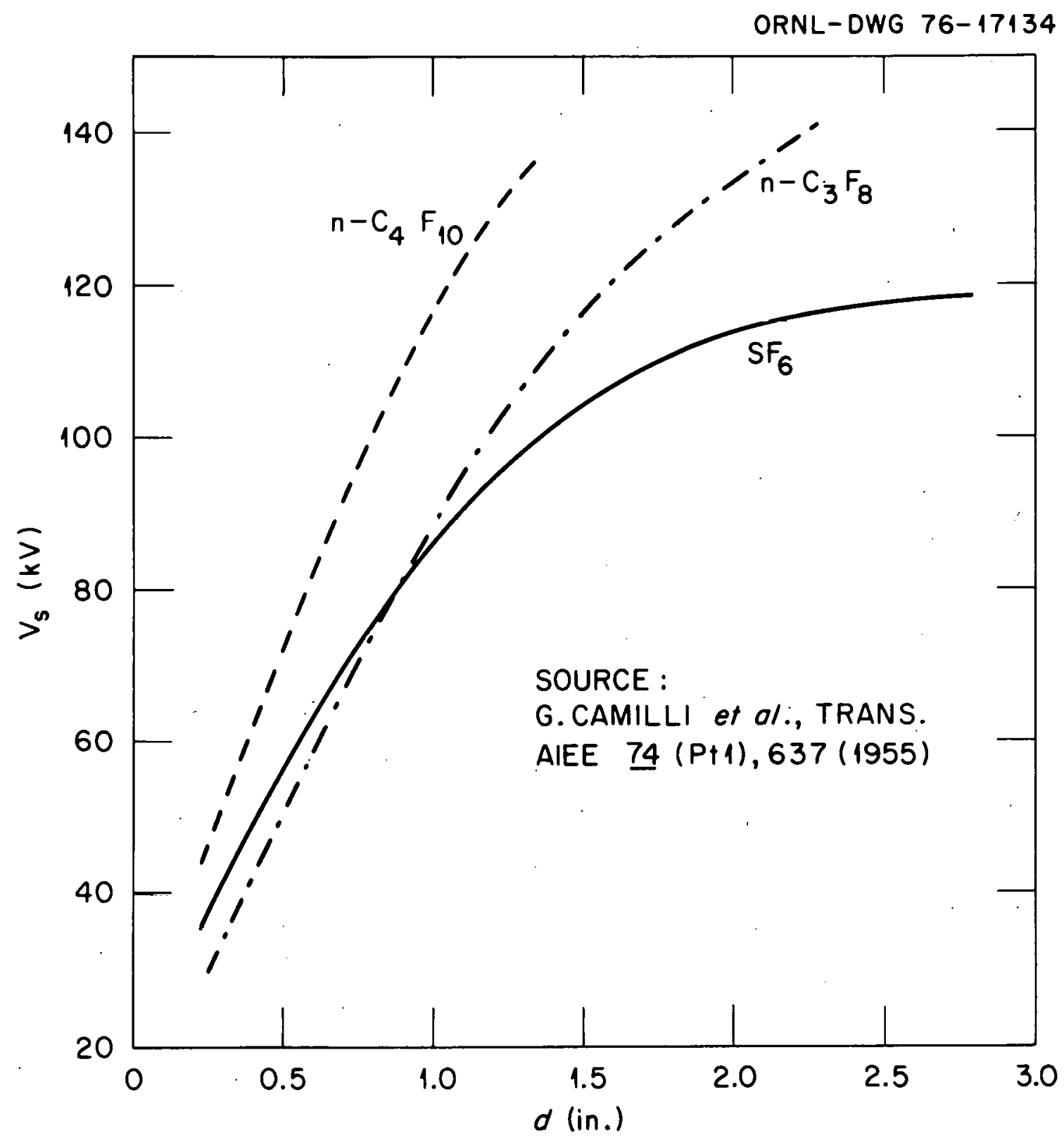

Fig. 4. Breakdown voltage versus gap for $S F_{6}, n-C_{4} F_{10}$ and $n-\mathrm{C}_{3} \mathrm{~F}_{8}$ at one atmosphere (based on data reported in Ref. 3). 


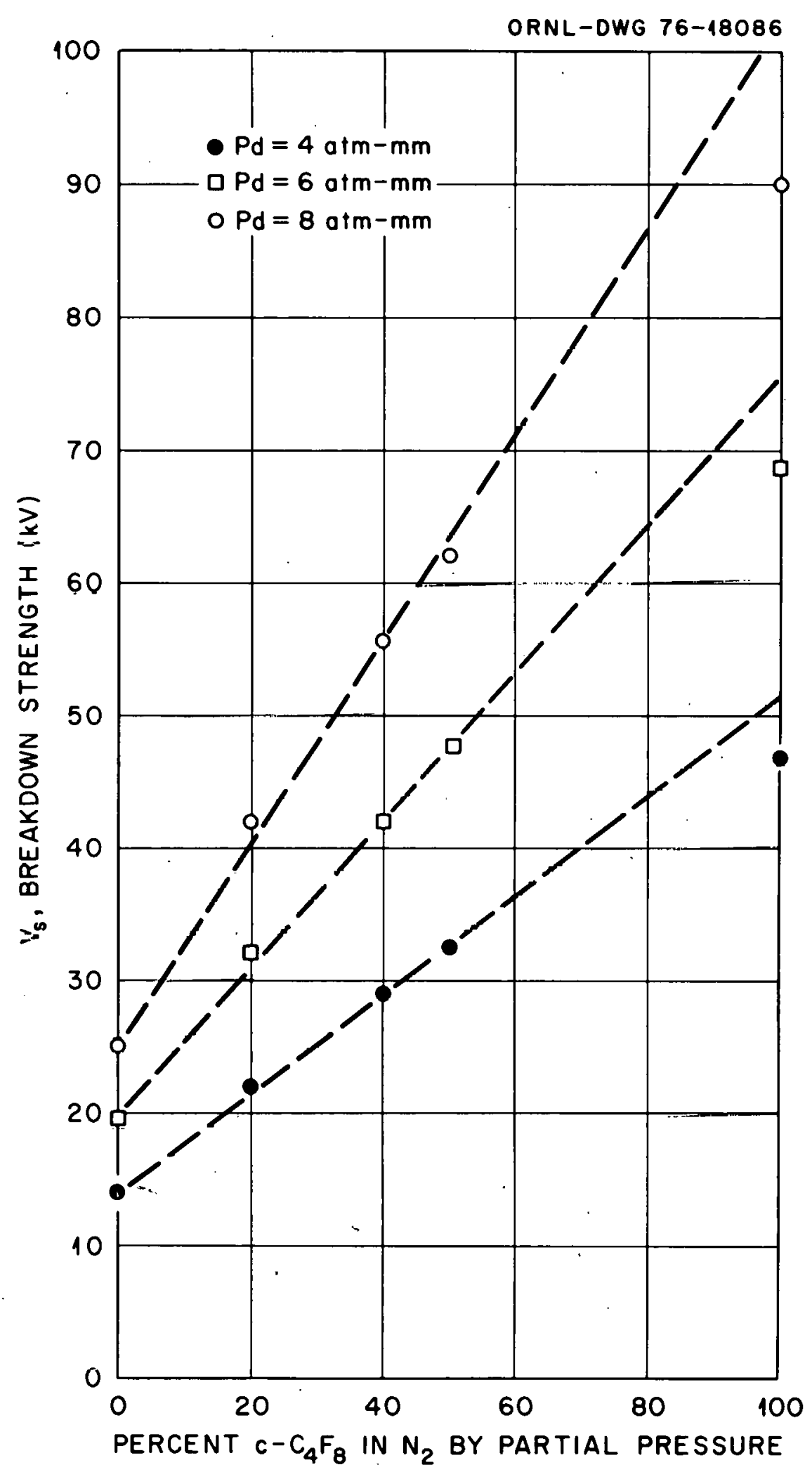

Fig. 5. Measured breakdown strengths of mixtures of $\mathrm{C}-\mathrm{C}_{4} \mathrm{~F}_{8}$ and $\mathrm{N}_{2}$. 
shown in Fig. 6. Further studies on mixtures using $\mathrm{N}_{2}+\mathrm{CO}_{2}$ and $\mathrm{C}_{3} \mathrm{~F}_{8}$ as abundant buffer gases are in progress. 


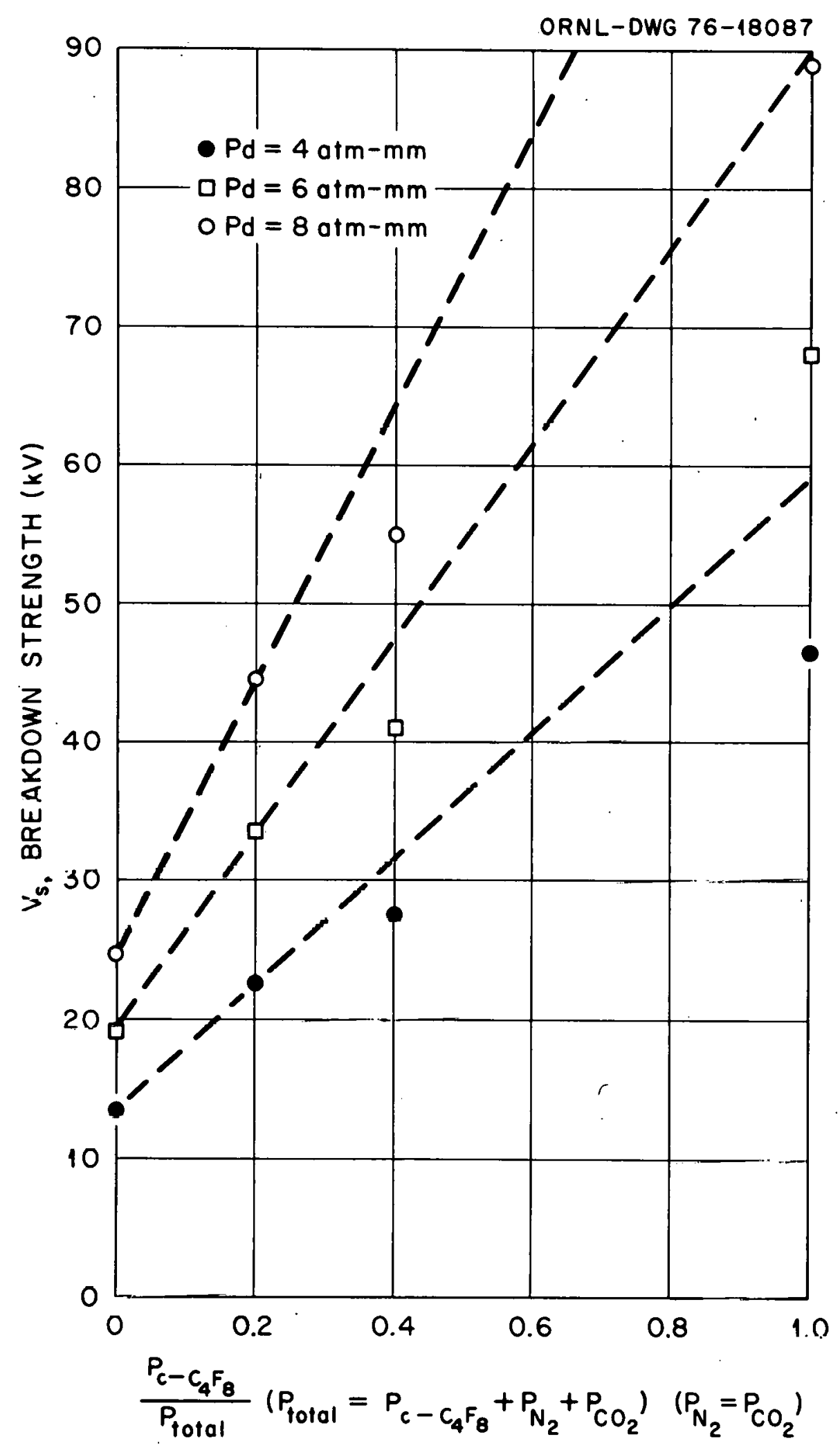

Fig. 6. Measured breakdown strengths of mixtures of $\mathrm{C}-\mathrm{C}_{4} \mathrm{~F}_{8}$ and $\mathrm{N}_{2}$ with $\mathrm{CO}_{2}$. 


\section{BASIC STUDIES}

During this quarter, we have finished the measurements of the electron attachment rate for iso- $\mathrm{C}_{4} \mathrm{~F}_{8}$ (for our technique see Ref. 4). We also have preliminary results for $\mathrm{C}_{4} \mathrm{~F}_{6}$. Figure 7 shows the measured electron attachment rate for $\mathrm{SF}_{6}, \mathrm{C}-\mathrm{C}_{4} \mathrm{~F}_{8}$, iso- $\mathrm{C}_{4} \mathrm{~F}_{8}$ and $\mathrm{C}_{4} \mathrm{~F}_{6}$. Figure 8 shows the electron attachment cross sections unfolded from Fig. 7 for these four gases. The cross-section curve for $\mathrm{C}_{4} \mathrm{~F}_{6}$ may be as much as $20 \%$ in error. This is primarily because we were unable to measure accurately extremely small amounts ( $\lesssim 10^{-4}$ torr) of this gas in our apparatus. However, with a new pressure-sensing device which we now have on hand we will be able to accurately measure the $C_{4} F_{6}$ pressure and to reduce this uncertainty in the absolute cross section. The functional dependence of the cross section on energy is, however, correct and is not affected by this uncertainty.

Our primary goal, of course, is to correlate the basic data (especially those on electron attachment and scattering) with breakdown measurements and to use this correlation to obtain the "best" possible insulators, as well as to develop a better understanding of the breakdown process itself. Figures 3 and 8 show an immediate and striking correlation. For each of these perfluorocarbons the attachment cross section is substantial at energies $\gtrsim 0.4 \mathrm{eV}$, whereas for $\mathrm{SF}_{6}$ the cross section is quite small in that energy region. The breakdown voltages for the former are seen (Fig. 3) to far exceed that for the latter. Our new measurements in iso- $\mathrm{C}_{4} \mathrm{~F}_{8}$ and $\mathrm{C}_{4} \mathrm{~F}_{6}$, therefore, seem to add support to the hypothesis put forward in our first quarterly report that electrons in the energy range $\sim 0.5$ to $\sim 2 \mathrm{eV}$ play a very important role in controlling the breakdown. 


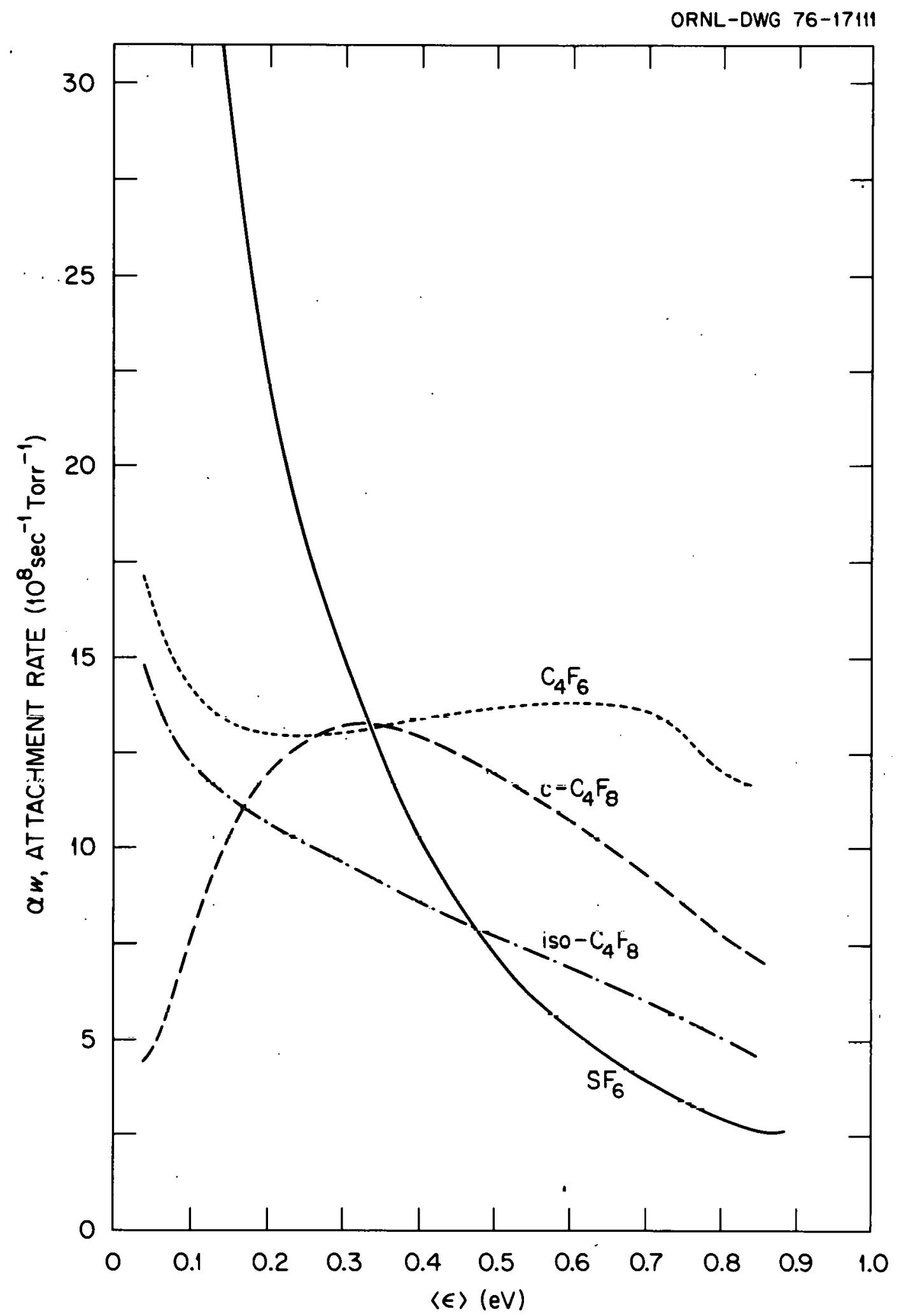

Fig. 7. Electron attachment rate versus mean electron energy for $\mathrm{C}_{4} \mathrm{~F}_{6}, \mathrm{C}-\mathrm{C}_{4} \mathrm{~F}_{8}$, iso $-\mathrm{C}_{4} \mathrm{~F}_{8}$ and $\mathrm{SF}_{6}$. 


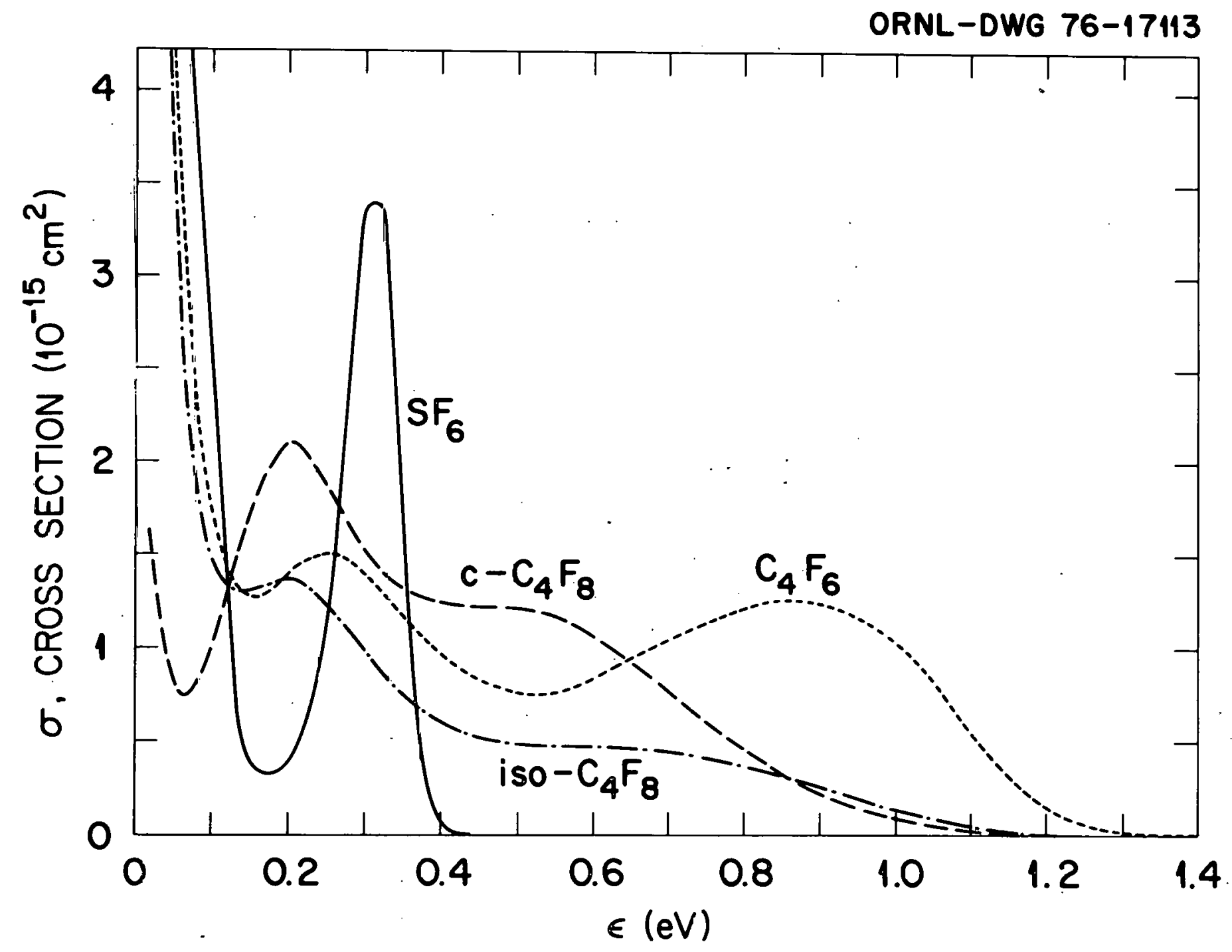

Fig. 8. Electron attachment cross section versus electron energy for $C_{4} F_{6}, C-C_{4} F_{8}$, iso $-C_{4} F_{8}$ and $S F_{6}$. 
Additionally, the fact that iso- $\mathrm{C}_{4} \mathrm{~F}_{8}$ and $\mathrm{C}_{4} \mathrm{~F}_{6}$ have high breakdown strengths points to another microscopic property of importance in gaseous dielectrics, namely, the inelastic scattering cross section. The larger the inelastic scattering cross sections for electrons (via direct and indirect excitation), the greater the effectiveness of the gas to extract energy from the free electron population in the gas and thus to inhibit breakdown.

In our first quarterly report ( $p p .44-45)$ we have provided information showing the effect on free electrons of the presence of multiple bonds in the gas molecules. The structures of the molecules in Fig. 3 whose breakdown strengths we have measured are the following:<smiles>FS(F)(F)(F)(F)F</smiles>

$\mathrm{SF}_{6}$<smiles>FC1(F)C(F)(F)C(F)(F)C1(F)F</smiles>

$\mathrm{e}-\mathrm{C}_{4} \mathrm{~F}_{8}$<smiles>FC(F)(F)C#CC(F)(F)F</smiles>

$C_{4} F_{6}$

$\mathrm{SF}_{6}$ and $\mathrm{C}-\mathrm{C}_{4} \mathrm{~F}_{8}$ have only single bonds, but iso- $\mathrm{C}_{4} \mathrm{~F}_{8}$ has one double bond and $\mathrm{C}_{4} \mathrm{~F}_{6}$ one triple bond. The influence of the double bond in iso $=\mathrm{C}_{4} \mathrm{~F}_{8}$ is clearly seen from the data in Figs. 3 and 8 . In Fig. 3 we see that iso- $\mathrm{C}_{4} \mathrm{~F}_{8}$ has a higher breakdown strength than $\mathrm{c}-\mathrm{C}_{4} \mathrm{~F}_{8}$, al though it can be 
observed from Fig. 8 that iso- $\mathrm{C}_{4} \mathrm{~F}_{8}$ does not attach electrons as well as $c-\mathrm{C}_{4} \mathrm{~F}_{8}$ does in the "critical" $0.4 \mathrm{eV}$ to $\sim 2.0 \mathrm{eV}$ range. Clearly, then, the higher dielectric strength for iso- $\mathrm{C}_{4} \mathrm{~F}_{8}$ can be attributed to the presence of the double bond and the associated higher inelastic scattering cross section at low energies ${ }^{5}$ (i.e., to its superior electron thermalizing properties) of iso- $\mathrm{C}_{4} \mathrm{~F}_{8}$ compared with $\mathrm{C}-\mathrm{C}_{4} \mathrm{~F}_{8}$.

We plan to extend our studies on the effects of the energy-dependent, electron-attachment cross section and inelastic energy losses on the breakdown strength to other available fluorocarbons. As an example, $\mathrm{C}_{3} \mathrm{~F}_{8}$ has a dielectric strength approximately that of $\mathrm{SF}_{6}$, yet from electron affinity considerations $C_{3} F_{8}$ should attach electrons very poorly (to form $\mathrm{C}_{3} \mathrm{~F}_{8}^{-}$at low energies). However, $\mathrm{C}_{3} \mathrm{~F}_{8}$ may attach electrons dissociatively, i.e., breakup of the molecule with the electron attaching to a fragment. ${ }^{6}$ This would be a higher energy (although lower cross section) attachment process. It can be seen from Fig. 4 that $C_{3} F_{8}$ excels over $\mathrm{SF}_{6}$ at higher $\mathrm{Pd}$ values. As it was stated earlier, we intend to investigate $\mathrm{C}_{3} \mathrm{~F}_{8}$ as a buffer gas in multicomponent mixtures. 


\section{v. CONTACTS}

In June we were visited by Professor A. Pedersen of The Technical University of Denmark. Dr. Pedersen presented a seminar on breakdown in insulating gases and participated in valuable discussions with the group. In July D. R. James attended the IEEE Summer Power Meeting and toured the Carey High Voltage Laboratories of the Bonneville Power Administration. In August L. G. Christophorou gave an invited lecture at the Gordon Research Conference on Radiation Physics and Chemistry and discussed various basic aspects of the program with a number of the participants. In September L. G. Christophorou presented two invited papers at the International Conference on Electrons in Fluids at Banff, Canada. A number of papers at this Conference dealt explicitly with breakdown. Discussions with many of the participants were indeed very valuable. In September, also, we were visited by Professor A. Bernas of the University of Paris and by Professor D. Schulte-Frohlinde of the Max-Planck Institute, Müiheim, Germany.

Robert $Y$. Pai is scheduled to present a paper on our results at the Gaseous Electronics Conference in October. Additionally, M. 0. Pace corresponded with various British laboratories about a future visit, viz., the Central Electricity Research Laboratory, the Central Electricity Generating Board and the Electrical Engineering Departments at the Universities of Liverpool, Manchester and Strathclyde. In this quarter, also, we continued to receive help from colleagues at Oak Ridge National Laboratory and The University of Tennessee, and many discussions were held with industry concerning experimental equipment. 


\section{PROJECTIONS}

Next quarter we expect to put the new controller into routine operation on apparatus 1 . On apparatus 2 the improved electrode mounting will be in use. The new chamber for the $300 \mathrm{kV}$ power supply will be designed and constructed. In the separate diverter experiment we plan to study time, range and reliability characteristics, first in air. The unitary systems studied so far in apparatus 1 will be studied at still higher Pd values in apparatus 2, while the study of mixtures will be transferred to apparatus 1 for economy of test gases. (We expect to receive the $300 \mathrm{kV}$ supply and put the third chamber into operation immediately thereafter.) Correlation between breakdown strength and fundamental processes will be extended to other fluorocarbons and other substances as well. Studies of the breakdown strength properties of mixtures will continue and so will the basic studies of dielectric gases. 


\section{REFERENCES}

1. L. G. Christophorou, D. R. James, R. Y. Pai, M. O. Pace, R. A. Mathis and D. W. Bouldin, High Voltage Research (Breakdown Strengths of Gaseous and Liquid Insulators), Report ORNL/TM-5604, September 1976.

2. G. S. Korshunov, V. V. Khmyrov, V. F. Vazhov and M. T. Pichugina, Instruments and Experimental Tcchniques 17, \#1, pt. 1, 1042 (1974).

3. G. Camilli, T. W. Liao and R. E. Plump, Trans. AIEE 74, pt. 1, 637 (1955).

4. L. G. Christophorou, Atomic and Molecular Radiation Physics, WileyInterscience, New York, 1971.

5. See L. G. Christophorou, R. P. BTaunstein and D. Pittman, Chem. Phys. Letters 22, 41 (1973).

6. Of course, in cases of molecular fragmentation the effect of the products on the gaseous dielectric's breakdown strength must be investigated. 
ORNL/TM-5713

INTERNAL DISTRIBUTION

1-2. Central Research Library

3. Document Reference Section

4-6. Laboratory Records

7. Laboratory Records, R.C.

8. ORNL Patent Office

9-35. Technical Information Center

36. J. A. Auxier

37. R. D. Birkhoff

38. D. W. Bould in

39. J. G. Carter

40-59. L. G. Christophorou

60. F. L. Culler

61-65. D. R. James
66. J. E. Jones, Jr.

67. H. M. Long

68. R. A. Mathis

69-73. M. 0. Pace

74-78. R. Y. Pai

79. H. Postma

80. C. R. Richmond

81. M. W. Rosenthal

82. S. W. Schwenterly

83. D. E. Tittle

84. M. K. Wilkerson

85. H. A. Wright

86. A. Zucker

\section{EXTERNAL DISTRIBUTION}

87. D. Allen, Division of Electric Energy Systems, Energy Research and Development Administration, Washington, D.C. 20545.

88. Director, Research and Technical Support Division, Oak Ridge Operations, Energy Research and Development Administration, Oak Ridge, Tennessee 37830 .

89. R. W. Flugum, Division of Electric Energy Systems, Energy Research and Development Administration, Washington, D.C. 20545.

90-105. T. F. Garrity, Division of Electric Energy Systems, Energy Research and Development Administration, Washington, D.C. 20545.

106. J. M. Googe, Department of Electrical Engineering, The University of Tennessee, Knoxville, Tennessee 37916.

107. D. Mayhew, Office of the Controller, Energy Research and Development Administration, Washington, D.C. 20545.

108. J. Mckeown, Assistant Administrator for Conservation, Energy Research and Development Administration, Washington, D.C. 20545. 